\title{
REVISTA TAMOIOS
}

\section{O Velho e o Novo Sindicalismo e a Formação do Sindicato Estadual dos Profissionais de Educação do Rio de Janeiro (SEPE)}

Rita de Cassia da Silva

\section{Introdução}

O objetivo deste trabalho é analisar as condições de criação do Sindicato Estadual dos Profissionais de Educação do Rio de Janeiro (SEPE), no contexto da mudança sociopolítica nacional em meados dos anos 70 e início da década de 80. Este trabalho divide-se em duas seções; a primeira busca examinar a emergência do chamado Novo Sindicalismo e suas implicações teóricas e políticas, a segunda busca compreender a criação do SEPE e sua relação no quadro do Novo Sindicalismo e da conjuntura política brasileira.

\section{A Era do Novo Sindicalismo}

A década de 50 foi marcada pela sobrevivência da legislação sindical corporativista, forjada no período autoritário do Estado Novo e na vigência da normalidade constitucional do pós-46. De acordo com Francisco Weffort (1981), subordinado ao regime populista então em vigor no país, o sindicalismo atingiu grande desenvolvimento; contudo, devido à crise política de 1964, sucumbe juntamente com o regime político.

Apesar da turbulência desse período, a sociedade brasileira conquistou espaço na participação política, surgindo inúmeros movimentos sociais (estudantis, feministas, bairristas, contra a carestia, etc.) articulados, ou 


\section{REVISTA TAMOIOS}

não, aos sindicatos, o que acelerou a crise do Regime Militar (governo Ernesto Geisel, 1974-79).

Sob uma estratégia de gradativa flexibilização, foram sendo traçados os rumos do processo de redemocratização do país e criado o Novo Sindicalismo, o que trouxe significativas mudanças às políticas trabalhistas nacionais, particularmente ao serem rompidos os limites estabelecidos pela lei antigreve, ou seja, o silêncio obrigatório da classe trabalhista em vigor desde a greve de Contagem e Osasco (1968).

Antunes (1995) salienta que a greve dos metalúrgicos do $A B C$ paulista (1978) culminou com a paralisação de outras categorias, abalando os pilares político-econômicos e administrativos da ditadura militar; em outro estudo (2003), esclarece que o ano de 1979 foi marcante na luta sindical do país, sacudido por cerca de 430 greves abrangentes de diversas categorias trabalhistas, sendo o movimento operário colocado num patamar privilegiado na luta contra o poder ditatorial, cujo modelo político-econômico e social já apresentava sinais de cansaço, abalado pela redução dos lucros em alguns setores da economia, retração dos investimentos e, mais especialmente, pela inflação incidente no custo de vida nacional.

$\mathrm{Na}$ década de 80, período de intensa atividade grevista, ocorreram significativas mudanças no contexto sindicalista do país, sobretudo a partir do movimento grevista do $A B C$ paulista, com a retomada das ações grevistas, explosão do sindicalismo rural, nascimento das centrais sindicais nas fábricas, elevação do índice de sindicalizações e alterações na estrutura sindical (pós-Constituição de 1988).

Sobretudo, tais alterações estruturais caracterizaram-se pela 


\section{REVISTA TAMOIOS}

organização e consolidação das centrais sindicais (CUT e CGT), cuja extensão organizacional nos setores assalariados médios e dos servidores públicos, em respectivo aumento do quantitativo de trabalhadores sindicalizados, teve como linha mestra os setores industrial e bancário. Contudo, a CUT e a CGT, segundo Antunes (2003), denotaram significativas divergências:

A CGT é a central sindical da ordem, aberta e dócil ao capital nacional e estrangeiro e que tem como eixo de sua ação a recusa aos confrontos mais amplos. Sua liderança estampa a penetração da ideologia burguesa junto ao movimento operário, quer através da vertente neo-liberal, quer através daqueles herdeiros do velho peleguismo que agora se pretende moderno. A CUT, por sua vez, nasceu em torno do Novo Sindicalismo, do sindicalismo mais combativo que se constituiu a partir de meados da década de 70 e aglutina sindicalistas independentes (isto é, sem militância anterior)...a Central Única dos Trabalhadores tem presença junto àqueles sindicatos mais expressivos, mais organizados, com maior tradição de lutas. (p. 69-70)

Originada no sindicalismo do período getulista, que vigorou até

a ditadura militar, e fortemente influenciada pelo Velho Sindicalismo, a Confederação Geral dos Trabalhadores (CGT) subsidiava-se por elevada fração da antiga burocracia sindical; em contrapartida, as características mais marcantes da CUT emanaram do Novo Sindicalismo, cujas feições políticas firmaram-se com as greves do ABC Paulista.

Alvarenga (1991) enfatiza que "a luta limitada ao mundo do trabalho [passou a abranger] o universo amplo da política partidária (...) tanto ao nível da sociedade como do Estado", à medida em que as classes trabalhadoras passaram a lutar por seus direitos.

Quanto à expressão "Novo Sindicalismo", afirmam Badaró (1996) e Alvarenga (1991), surgiu num contexto onde a ação dos sindicatos 


\section{REVISTA TAMOIOS}

subordinava-se ao comando dos sindicalistas tidos como "autênticos", passando a ser utilizada pelos estudiosos do tema.

Com relação aos anteriores sindicalismos, Moisés $(1981)^{1}$ e Almeida $(1984)^{2}$ esclarecem que o Novo Sindicalismo

(...) opunha-se, obviamente, ao imobilismo do sindicalismo controlado e reprimido pelos governos militares, mas opunha-se também às formas consideradas como dominantes no movimento sindical do pré-64, genericamente denominado "sindicalismo populista". (in: BADARÓ, 1996, p.77)

No entender de Moisés (1981) e Almeida (1984), haviam diferenças na esfera de atuação e na composição entre o sindicalismo da chamada "Era Populista" e o Novo Sindicalismo: no primeiro, os sindicatos dos setores de serviços e do funcionalismo foram combatidos mais intensamente; no segundo, isto ocorreu com os dos setores industriais de ponta e, por conseguinte, passaram a ser mais numerosas as greves por empresas, comparativamente às greves por categorias.

A respeito da expressão "Novo Sindicalismo", Badaró (1996) enfatiza ter surgido no contexto das práticas sindicais tidas como inovadoras, emergentes com as greves e os discursos revolucionários dos novos líderes sindicais; o Novo Sindicalismo, portanto, surgiu da noção de ser o Velho Sindicalismo marcado pela repressão ao movimento sindical, atrelamento do sindicato ao Estado e peleguismo, a partir da urgência dos sindicalistas em construir uma identidade capaz de produzir reconhecimento e delimitar fronteiras, conforme apontou Luís Inácio Lula da Silva, quando à frente da diretoria do Sindicato dos Metalúrgicos de São Bernardo: 
O dirigente sindical que se preza não pode em nenhum momento ver o sindicato como órgão empregatício que Ihe dê um status. O dirigente sindical que se preza não pode deixar de denunciar as arbitrariedades existentes dentro de suas categorias. O pelego é a omissão do movimento sindical brasileiro. É de muita recepção mas de pouca participação. Um dirigente sindical que se preza não deveria se sujeitar a ser um vogal, um juiz classista, apenas para ganhar dinheiro. (in: BADARÓ, 1996)

O discurso de Lula reporta à construção de uma nova identidade a partir da rejeição, tanto do sindicalismo conformado do pós-64, quanto das lideranças sindicais que se proclamavam combativas ao período anterior ao golpe militar, demonstrando que ambos os grupos poderiam ser resumidos a um único grupo, o dos pelegos.

Um olhar mais demorado sobre o Velho Sindicalismo deixa perceber que, nos anos 30 , a relação do Estado populista com a chamada classe trabalhadora dá origem ao "sindicalismo de massa", ou seja, ao sindicato atrelado ao Estado, gerando o "pelego" (pessoa de confiança, determinadora de programas sindicais, bem como de atividades recreativas e assistenciais).

Nesse período foi iniciada a reorganização do movimento operário através de uma legislação trabalhista (criação do imposto sindical, da justiça trabalhista e do salário mínimo) e da normatização de representação da classe trabalhadora, o governo busca transformar as organizações sindicais em órgãos de colaboração de classe e base de seu poder político.

A partir da criação e ampliação dos espaços ocupados pela CUT (década de 80) o Novo Sindicalismo passa a ser a tendência dominante, identificando o movimento sindical brasileiro; a onda grevista (1983-89) deixaria impressa a década de 80 como a "Era do Novo Sindicalismo", cuja escalada 


\section{REVISTA TAMOIOS}

sofre uma inflexão ao raiar da década seguinte; isto porque, de 1990 em diante, o impacto da reestruturação produtiva na economia capitalista forjou inúmeras transformações sindicais em nível nacional:

A conjuntura dos anos 1990 foi marcada pelo desemprego estrutural, políticas econômicas neoliberais (abertura da economia, privatização, desregulamentação das relações trabalhistas etc.) e agressiva ação empresarial para enquadramento dos trabalhadores que permaneceram em seus empregos nas novas metas de crescimento da produtividade. Essas características ajudam a entender o refluxo da ação sindical, marcado não apenas pelo menor número de greves, mas também pela adesão de muitas das direções da CUT a um ideário de parcerias e colaboração com o empresário, na busca de soluções pactuadas, que pudessem frear as perdas dos trabalhadores. (BADARÓ, 2003, p. 71)

Sobre esse período de crise político-administrativa, Santana (2003) explana que, sob o impacto das mudanças econômicas então empreendidas, o sindicalismo brasileiro atravessou um processo de reorientação de suas práticas e estratégias; comparativamente à década de 80 , houve certa redução das atividades mobilizadoras e, por conseguinte, o perfil de filiação sofreu decréscimo nos setores bancário e industrial.

Contudo, apesar da crise, foi mantida certa estabilidade de filiação aos diversos sindicatos nacionais; acompanhando as transformações do mercado de trabalho, o sindicalismo conseguiu se expandir e consolidar nas áreas de educação e saúde, bem como angariar a adesão de alguns estratos populares, como a dos trabalhadores de maior escolaridade $\mathrm{e}$ mulheres.

Alguns autores fazem relevantes críticas ao Novo Sindicalismo demonstrando que, apesar de "novo", mantém alguns postulados do Velho 


\section{REVISTA TAMOIOS}

Sindicalismo, verdadeiros empecilhos ao bom êxito de suas propostas:

Com aprovação da Constituição de 1988 e as eleições presidenciais de 1989, consolidando a redemocratização, encerra-se, em certo sentido, a "era" do novo sindicalismo brasileiro. O fim do controle do Ministério do Trabalho sobre os sindicatos, do "estatuto-padrão" e da proibição de sindicalização do funcionalismo público foram conquistas inscritas naquela Carta.Mas a manutenção da unicidade sindical, do monopólio da representação, do imposto sindical e do poder normativo da Justiça do Trabalho indicaram que o novo sindicalismo não foi totalmente bem-sucedido em sua proposta, pois a estrutura sindical oficial, como a herança corporativista, continuou pesando sobre os sindicatos. Também internamente ao sindicalismo da CUT e no plano mais geral das mobilizações da classe trabalhadora, os anos seguintes marcariam uma grande mudança. (BADARÓ, 2003, p.70)

Dessa forma, o Novo Sindicalismo mantinha o tradicional vínculo com o Estado: um marcante monopólio de representações e grande poder de tributação sindical. Sua trajetória pontuou-se pela significativa luta dos trabalhadores contra a exploração econômica como, por exemplo, o movimento grevista do ABC Paulista (1978), com pauta à consolidação da democracia no país, com ênfase à cessão de espaço à classe trabalhadora nas discussões sobre os horizontes políticos, econômicos e administrativos da nação, em nítida resistência à exploração da classe trabalhadora por determinados setores produtivos, tendo em vista as emergentes transformações da sociedade.

É nesse contexto que ganhou corpo a Sociedade Estadual dos Professores (atual SEPE) e seu histórico movimento grevista (1979).

\section{A Criação do SEPE}




\section{REVISTA TAMOIOS}

Da fusão entre a Sociedade Estadual dos Professores (SEP) e a União dos Professores do Rio de Janeiro (1979), surgiu o SEPE/RJ, numa trajetória pontuada por várias denominações, assumindo esta nomenclatura na Assembléia Geral de 12 de dezembro de $1988^{3}$.

Em 1976, um grupo de professores reuniu-se para debater, dentre outros assuntos, a disposição do governo para unificar História e Geografia em Estudos Sociais no $2^{\circ}$ grau, a exemplo do que já havia feito no $1^{\circ}$ grau (lei 5692/71); ao término de um longo debate, chegaram à conclusão que deveriam se formalizar numa organização, no intuito encaminhar as questões da educação para os órgãos competentes; assim, foi postulada a criação do SEP (16-07-1977); em 1978, foi construído o primeiro núcleo, em Niterói, seguido da criação do segundo núcleo, no município de Campos (ALVARENGA, 1995).

Sob a ótica política, de acordo com Alvarenga (1991), o SEP agrupou-se em dois segmentos:

- Segmento constituído por professores originários do movimento estudantil, recém-saídos das Universidades, com uma bagagem teórica de "radicalização intelectual" e forte perspectiva político-partidária, bastante defasados em termos de conhecimento do cotidiano escolar e da docência; de acordo com a entrevista cedida pelo professor Godofredo Pinto:

Eram organizados (MEP - Movimento de Emancipação do Proletariado: CS - Convergência Socialista), e formam a nível nacional o MOAP (Movimento de Oposição Aberta dos Professores). Tinham perspectiva de não se inserirem em uma ampla frente democrática, mas de marcar posição em campo próprio e específico. Haviam também setores que representavam outros segmentos 


\section{REVISTA TAMOIOS}

políticos que, no Rio de Janeiro, foram caracterizados por "Blocão" (MR-8, PCs, AP), mais aproximados a bandeiras democráticas gerais. (in: ALVARENGA, 1991)

- Segmento constituído por professores primários e professores formados em faculdades particulares (onde o processo de teorização política e crítica, se existente, era fortemente reprimido), com larga experiência do cotidiano escolar e profissional, que assumiam uma postura espontaneísta face o processo de mobilização (ALVARENGA, 1991).

Apesar dessa diferenciação política, ambos segmentos participaram das primeiras organizações para criar um movimento com vista à tomada de sindicatos e associações pelegas, ou que fossem suportes na atuação dos sindicatos de professores particulares. Este contexto de confluência de projetos e atores criou condições para o surgimento da Sociedade Estadual dos Professores (SEP).

De acordo com Sobreira (1989), o contato entre a entidade e a categoria era feito através dos boletins periódicos do SEP; entre setembro de 1977 e julho de 1979 foram publicados oito boletins, seis ordinários e dois especiais; dentre outros informativos, o primeiro boletim (setembro de 1977), apontava à necessidade de existirem núcleos por unidade escolar visto como indispensáveis para o bom funcionamento das assembléias mensais da entidade.

É importante frisar a relação do SEP com a APERJ (Associação dos professores do Estado do Rio de Janeiro), a UP/RJ (União dos Professores do Rio de Janeiro) e o SINPRO (Sindicato dos Professores do Rio de Janeiro, fundado em1931).

Os integrantes do SINPRO de orientação esquerdista (AP- 


\section{REVISTA TAMOIOS}

Ação popular) saem desse sindicato e vão constituir o SEP, o qual, após exaustivos debates, se funde à APERJ e à UP/RJ (julho de 1979), sendo criado o CEP (Centro Estadual de Professores), cuja ampliação do quadro de filiados, em inclusão dos demais profissionais de educação, aprovada no III Congresso do CEP (outubro de 1987), incidiu em nova nomenclatura à entidade: CEPE ${ }^{5}$ (Centro Estadual dos Profissionais de Educação).

Dando ênfase a questão dos integrantes de orientações esquerdista que saíram do SINPRO e formaram o SEP, Sobreira (1988) revela:

“...Não bastassem estas dificuldades, na Convenção Coletiva Salarial de 1977, ocorrem sérios atritos entre o grupo e a diretoria do SINPRO-RJ. Esta, sem qualquer respeito às deliberações da assembléia realizada para discutir a pauta da Convenção, assina o acordo coletivo para 1977. Em seguida, as comissões de dinamização do Sindicato são dissolvidas e proibidas reuniões nas suas dependências sem a autorização prévia da direção"(SOBREIRA,1988, p.78)

Quando ocorreu o atrito entre os membros do AP e os diretores do SINPRO e a separação entre as partes, somente os elementos ligados ao PCB continuavam a investir na participação no Sindicato, visando a sua retomada, os demais grupos como AP e Mr-8 defendia a construção de uma entidade de professores e o restante das correntes opta pela organização do tipo paulista como o (MUP) Movimento de Unidade de Professores.(SOBREIRA,1998).

A criação de uma nova entidade, segundo Sobreira (1998) se impõe como alternativa devido a dois fatores: o impedimento legal de sindicalização 


\section{REVISTA TAMOIOS}

de professores públicos e os fortes atritos descritos acima, entre os membros do grupo e a diretoria do SINPRO -RJ.

Segundo Alvarenga (1995), em 1987 o CEPE filiou-se e à CPB (Confederação dos Professores do Brasil), hoje CNTE (Confederação Nacional dos Trabalhadores), e à CUT (Central Única dos Trabalhadores), assumindo junto a estas e a outros sindicatos, a luta pela autonomia e liberdade sindical; tentando romper com a estrutura sindical oficial, instituiu, dentre outras medidas, o não recolhimento do imposto sindical, embora respeitasse os marcos constitucionais que mantêm a estrutura corporativista atrelada ao Estado.

Em dezembro de 1987, apesar da decisão de denominar a entidade sindical CEPE como SEPE (Sindicato Estadual dos Profissionais de Educação), com base territorial no Estado do Rio de Janeiro, o reconhecimento legal da instituição como sindicato só ocorreu em 28 de julho de 1989.

Embora a Constituição Federal de 1988 tenha trazido e consagrado inúmeras mudanças (direito à sindicalização dos funcionários públicos, extensão dos direitos sindicais para o campo, liberdade de associação sindical sem autorização prévia ou interferência do Estado e suas interferência etc.), foram mantidos o imposto sindical (elemento mais forte de atrelamento do sindicato ao Estado), a organização por categoria profissional e não por ramo da atividade, o fortalecimento das Confederações e o sindicato único.

Quanto à conquista do sindicato único, decorreu das lutas concretas encaminhadas pelos trabalhadores em favor da sua autonomia e 


\section{REVISTA TAMOIOS}

liberdade sindicais, e em defesa do princípio dessa organização e respectivas ações.

De fato, o texto da Constituição de 1988 apresenta certas ambigüidades: por um lado, a permanência, no seu conteúdo, de vários pontos tradicionais; por outro lado, medidas que, teoricamente, correspondem a certos anseios dos trabalhadores organizados e que se mantiveram por necessidade dos interesses do Estado.

A princípio, o SEPE era unicamente zonal; os núcleos regionais começaram a ser criados na década de 80; atualmente é formado por 9 núcleos regionais na capital e 35 municipais, no interior do Estado.

Atualmente, o SEPE/RJ está estruturado nos municípios de Angra dos Reis, Barra do Piraí, Barra Mansa, Belford Roxo, Cabo Frio, Cachoeiras de Macacu, Campos, Cantagalo, Conceição de Macacu, Cordeiro, Duque de Caxias, Itaboraí, Itaguaí, Itaocara, Itaperuna, Itatiaia, Macaé, Magé, Mangaratiba, Maricá, Mendes, Niterói, Nova Friburgo, Nova Iguaçu, Nilópolis, Pinheiral, Porciúncula, Resende, Rio Bonito, São Gonçalo, São João de Meriti, Teresópolis, Três Rios, Valença e Volta Redonda.

Desde a sua criação, as diretrizes estatutárias do SEPE consistem em reunir e congregar os profissionais de educação, ativos e aposentados, cooperativados e terceirizados, relacionados direta ou indiretamente com órgãos públicos de educação, das redes Estadual e Municipal, bem como aqueles que "mantenham registro/vínculo com rede privada e lou Federal e, ainda, os professores que possuam registro no MEC" (SEPE/RJ, 2000, p.1-art 1º, in: Silver, 2002, p. 89); em 2002, o SEPE/RJ já contava com cerca de 40 mil filiados, 20.272 da rede estadual e 15.595 da rede 


\section{REVISTA TAMOIOS}

municipal do Rio de janeiro.

Instanciado ao Congresso Estadual, Conferência Estadual, Assembléia geral, Conselho Deliberativo, Diretoria Estadual e Conselho Fiscal, o sindicato é dirigido por um colegiado composto por 48 membros; sua estrutura de funcionamento divide-se em Coordenadorias (Geral, da Capital; do Interior e Grande Rio) e Secretarias de Organização, Finanças, Imprensa e Comunicação, de Aposentados, Funcionários Administrativos, de Assuntos Educacionais, de Cultura e Formação Sindical, de Assuntos Jurídicos e Funcionais, de Gênero, Anti-racismo e Orientação Sexual, de Saúde. (SEPE/RJ, Art.36, in: Silver, 2002, p.91).

Outro dado importante sobre este sindicato é o das greves das categorias, que levaram à conscientização política e de classe de um considerável contingente profissional, muito também devido à possibilidade de um contato mais estreito com os dirigentes sindicais e criação de um espaço para discussão nas unidades escolares.

\section{Breve Histórico dos Movimentos Grevistas}

O ano de 1979 foi marcado por um contexto de forte mobilização social, período em que eclodiu a primeira greve dos profissionais de educação, cujas reivindicações eram por um piso salarial em torno de cinco salários mínimos. Deflagrado em 12 março de 1979, ainda no final do governo de Faria Lima, movimento grevista prolongou-se por duas semanas até obter a aprovação do novo governo estadual (Chagas Freitas), que se comprometeu a atender a maior parte de suas reivindicações em 30 dias, promessa que não 


\section{REVISTA TAMOIOS}

foi concretizada em tempo hábil, provocando uma nova greve, a qual teve grande repercussão na imprensa, sendo manchete diária na primeira página da imprensa nacional.(FREIRE,1999)

Período de grande ebulição, entre março e agosto de 1979, houve uma acentuada divisão entre os coordenadores do SEPE, ante a possibilidade de retorno, ou não, à greve; segundo Badaró (1996), se a princípio o movimento tinha um caráter legal não-sindical, parecendo derivar de uma coesão maior, mais à frente dividiu-se: identificado com o Novo Sindicalismo, um grupo defendia a greve como instrumento de combate à estrutura sindical e à ditadura, uma arma para conquistas salariais; o outro grupo recomendava prudência na estratégia de aprofundamento da transição democrática.

Após dez dias de confronto aberto com o governo do estado (período em que foi decretada pelo governo federal a ilegalidade do movimento, com líderes do professorado detidos, retenção do pagamento, dissolução de entidades representativas do magistério), foi estabelecida mediação entre as partes, através do empenho de uma comissão de deputados federais e estaduais de diversas correntes do MDB.

Daí em diante houve o recuo tático que resultou no término da greve no dia 23 de agosto, dois dias após o governador Chagas Freitas emitir nota oficial em que dava sua versão dos fatos e atendia as reivindicações da classe em termos de efetivação dos contratados, regulamentação da regência de turmas e novo plano de vencimentos, assegurando então que, estabelecida a ordem, determinaria o "pagamento de todos os servidores da Secretaria de Educação, sem exceção"6. Reaberto em 1982, o SEPE retornou à campanha 


\section{REVISTA TAMOIOS}

de filiação em 1984, conquistando os descontos das mensalidades em folha.

É essencial enfocar a greve do magistério ocorrida em 1986, no governo de Leonel Brizola, cujos discursos de campanha eleitoral ressaltavam a prioridade que daria à educação, gerando enorme expectativa quanto à sua administração; expectativa sobretudo esvaziada pelo não atendimento à proposta do Plano de Carreira, vista em 1984 a categoria já realizar assembléias nesse intuito, com elevada concentração de profissionais altamente interessados (SILVER, 2002).

A luta pelo Plano de Carreira estendeu-se até 1986, sem qualquer resposta do governo; em 23 de março, a categoria votou pela greve, derrotando a proposta de paralisações. Em todo o país a onda de greve se estendia diante do arrocho salarial decretado pelo então presidente José Sarney, que buscava controlar o alto índice de inflação através do congelamento dos preços e salários.

Conforme registro do jornal O Dia (RJ, 01/04/86, p. 1. $)^{7}$, essa greve obteve forte adesão da categoria (cerca de 25 mil professores, cujas assembléias lotavam o Maracanãzinho): "Todos os estabelecimentos da rede de ensino do Estado e do Município não funcionaram ontem devido à greve dos professores, que estão cobrando uma resposta do Governo Brizola, sobre o Plano de Carreira da classe e melhoria do piso salarial". A greve foi deflagrada não só pelo não cumprimento do Plano de Carreira, mas também porque outras reivindicações não foram contempladas conforme o previsto.

A conquista do Plano de Carreira (cuja aplicabilidade regulamentar previa o enquadramento por formação, categoria, progressão e controle) e a formação da primeira comissão de aposentados da entidade, 


\section{REVISTA TAMOIOS}

fortalecendo as reivindicações sindicais respectivamente à almejada paridade no ano seguinte, foi marcante para o sindicato na luta pelos direitos da categoria.

$\mathrm{Na}$ ostensiva repressão ao movimento grevista deflagrado em 13 de junho de 1987 (governo de Moreira Franco), houve intervenção policial durante as passeatas e corte de ponto; após 69 dias de greve, a rede estadual decidiu pela suspensão da greve.

Com isso ficou nítido que logo seria deflagrada nova greve, pois além de não conquistar o indexador e a data base, a categoria perdeu 0 gatilho salarial, mecanismo que garantia a reposição das perdas salariais sempre que a inflação atingisse um índice previamente convencionado.

Assim, em 1988 eclodiu uma greve que duraria 89 dias; foi suspensa sem que a categoria fosse atendida numa de suas principais reivindicações: conquistar o indexador de salários. De concreto, conseguiu apenas algumas reivindicações de caráter mais geral: reforma das unidades escolares; atualização do estatuto do magistério; exame das políticas pedagógicas do $1^{\circ}$ e $2^{\circ}$ grau e do Supletivo; revisão da legislação sobre a eleição de diretores de escolas; efetivação dos professores seletistas; concessão de licença sindical; exame das situações concretas decorrentes da paralisação (SILVER, 2002).

Se a greve de 1979 foi historicamente marcante, e se após o refluxo do início da década de 80 a luta dos trabalhadores foi retomada (a partir de 1985, com destaque às greves de 1986/87), a greve de 1988 pode ser considerada a última grande greve do SEPE/RJ.

Sob influência da onda neoliberal que atingiu os países da 


\section{REVISTA TAMOIOS}

América Latina (década de 80 ), a retomada do movimento sindical na década de 90 atingiu diversas categorias em todo o território nacional; a eleição do presidente Collor de Melo e a decorrente recessão econômica de 1990-92 concorreram para que a atividade grevista fosse significativamente reduzida:

A década de 1990- não há como negar - foi um período difícil para o sindicalismo no Brasil. Os sindicalistas, apesar de continuarem a ser um movimento social importante, vêm sua capacidade de intervenção na luta política e social bastante reduzida. O SEPE/RJ está inserido nesse contexto de implementação de uma ideologia e uma política neoliberal e (...) passa enfrentar aparente um processo de desmobilização e redução de participação da categoria, inclusive nos períodos de greve. (SILVER, 2002, p.119)

De fato, foi no período de 1986 a 1988 que o movimento grevista atingiu seu ápice. Na década de 90, a participação da categoria em assembléias esteve bastante reduzida devido às dificuldades de mobilização, denotadamente pela conjuntura do neoliberalismo nacional e respectiva ideologia veiculada pela mídia, em desvalorização do funcionalismo público.

Antagonizada, a questão neoliberal, à política de bem-estar social, em drástica redução da responsabilidade governamental, na esfera educacional é nítido o processo de subordinação em termos de delimitação dos conteúdos e gestão do processo educativo que, num aspecto mais geral, é demarcada pela exigência de polivalência, cujo conceito, segundo Frigoto (1996), é de cunho mais operacional, indicando a demanda por um "novo trabalhador".

Nesse contexto, segundo o Caderno do $\mathrm{SEPE}^{8}$, perdendo, o sindicato, sua força de mobilização, o Estado aproveitou o ensejo para retomar o controle sobre a rede escolar, organizando-a segundo os interesses da classe dominante, na busca por fortalecer sua hegemonia sobre a escola 


\section{REVISTA TAMOIOS}

pública, parcialmente perdida na década anterior, através do seguinte processo: atrelamento da educação aos estreitos objetivos de preparo para o trabalho, isto é, para que o aluno possa competir no mercado de trabalho nacional e/ou estrangeiro; utilização da educação como veículo de transmissão das idéias que proclamam a excelência da livre iniciativa e do livre mercado. Para tanto, os sindicatos e os movimentos organizados precisara ser desarticulados, desautorizados e enfraquecidos, a que não desmascarassem o pretenso discurso hegemônico.

\section{Notas}

1 - In: Revista de Cultura e Política, № 5 e 6. Rio de Janeiro: Paz e Terra, 1981.

2 - In: Sociedade e Política no Brasil pós-64. 2ª ed. São Paulo: Brasiliense, 1984.

3 - As principais denominações do SEPE ao longo de sua trajetória foram: Associação de professores do Estado do Rio de Janeiro - APRJ (1977); Sociedade Estadual dos Professores - SEP (1977-79); Centro Estadual de Professores - CEP (1979-87); Centro Estadual dos Profissionais de Educação CEPE (outubro de1987) e Sindicato Estadual dos profissionais de Educação SEPE (dezembro de 87).

4 - Sociedade Estadual de Professores.

5 - Revista do SEPE, ano I, n¹.

6 - In: Jornal do Brasil, 24-7-1979.

7 - In: Silver, 2002, p. 113.

8 - Caderno do SEPE 3,1999, p.78 